\title{
SISTEM DETEKSI STRUKTUR KALIMAT BAHASA ARAB MENGGUNAKAN ALGORITMA LIGHT STEMMING
}

\author{
Mudafiq Riyan Pratama ${ }^{1}$, Muhammad Yunus ${ }^{2}$ \\ ${ }^{1,2}$ Program Studi Rekam Medik, Jurusan Kesehatan, Politeknik Negeri Jember \\ J1. Mastrip, Jember, Jawa Timur \\ Email : ${ }^{1}$ mudafiq.riyan@ polije.ac.id, ${ }^{2}$ m.yunus@polije.ac.id
}

\begin{abstract}
ABSTRAK
Untuk memahami bahasa Arab, perlu mempelajari ilmu nahwu. Ilmu nahwu merupakan ilmu yang mempelajari tata kalimat bahasa Arab. Dengan belajar ilmu nahwu, bisa membedakan subjek, predikat, dan objek dalam kalimat. Salah satu bidang dalam dunia komputer yang mengkaji tentang pengolahan bahasa manusia adalah Natural Language Processing (NLP) yaitu pemrosesan bahasa alami manusia melalui analisis sintaksis terhadap struktur kalimat. Salah satu metode dalam menganalisis sintaksis kalimat adalah stemming. Salah satu varian dari algoritma stemming adalah algoritma Light Stemming. Algoritma Light Stemming adalah algoritma yang hanya menghilangkan imbuhan depan (prefix) dan imbuhan belakang (sufix). Berdasarkan pengujian yang dilakukan, algoritma light stemming mampu mendeteksi ilmu nahwunya dengan tingkat keberhasilan sebesar $82.22 \%$. Tingkat kegagalan $17.78 \%$ terjadi karena pada kata yang tidak memiliki imbuhan akan dideteksi secara otomatis jenisnya $f i$ 'il (kata kerja), padahal faktanya bisa jadi jenisnya adalah isim (kata benda), serta gagalnya hasil deteksi juga dikarenakan tidak mampu melakukan stemming pada kata yang imbuhannya ditengah, karena memang proses light stemming hanya menghilangkan imbuhan depan dan imbuhan belakang.
\end{abstract}

Kata kunci: bahasa arab, ilmu nahwu, natural language processing, light stemming, sufix, prefix

\begin{abstract}
To understand Arabic, it is necessary to study nahwu theory. Nahwu theory is the study of structure of Arabic sentences. By learning nahwu, being able to distinguish subjects, predicates and objects in sentences. One of the fields in the computer that studies about human language processing is NLP (Natural Language Processing), which is natural human language processing through syntactic analysis of sentences structure. One method to analyzing syntactic of sentences is stemming. One variant of the stemming algorithm is Light Stemming algorithm. Light Stemming algorithm is an algorithm that only removes prefix and sufix. Based on the tests conducted, the light stemming algorithm is able to detect nahwu with an accuracy rate of $82.22 \%$. The $17.78 \%$ failure rate occurs because words that do not have an affix will be detected automatically the type is fi'il (verb), even though the fact may be that the type is isim (noun), and the failure of the detection results is also due to not being able to stemming the words that have affix in the middle (infix), because indeed the process of light stemming only eliminates the sufix and prefix.
\end{abstract}

Keywords: arabic, nahwu theory, natural language processing, light stemming, sufix, prefix

Author Korespondensi (Mudafiq Riyan Pratama)

Email : mudafiq.riyan@polije.ac.id

\section{PENDAHULUAN}

Bahasa Arab adalah salah satu bahasa tertua di dunia. yang juga termasuk bahasa dengan peringkat keempat yang paling banyak digunakan di dunia, dengan jumlah populasi pengguna sebanyak 315 juta orang di tahun 2018 dan bahasa yang tersebar di lebih dari 25 negara [1]. Bahasa Arab juga menjadi bahasa resminya umat Islam, karena dalam ibadahnya umat Islam seperti bacaan shalat, doa, dan Al-Qur'an menggunakan bahasa Arab.

Dalam memahami bahasa Arab, perlu mempelajari ilmu nahwu. Ilmu nahwu merupakan ilmu yang mempelajari tata kalimat berbahasa arab yang benar, dengan belajar ilmu nahwu maka kita bisa menguasai bahasa arab dengan baik serta bisa mengerti perubahan-perubahan kata tersebut, walaupun tidak memakai harokat [2]. Dengan memahami 
ilmu nahwu, seseorang akan bisa membedakan antara pelaku (fa'il) dan objek (maf'ul bih). Dengan memahami ilmu nahwu, seseorang akan mengenali keadaan akhir dari suatu kata, apakah ia bisa berubah akhirannya ataukah tetap. Dengan ilmu nahwu pula seseorang akan bisa membaca akhir kata dengan benar, apakah ia harus dibaca dhammah, fat-hah, atau kasrah [3].

Salah satu bidang dalam dunia komputer yang mengkaji tentang pengolahan bahasa manusia adalah Natural Language Processing (NLP). NLP merupakan komputasi linguistik yang berkaitan dengan interaksi antara komputer dan manusia melalui bahasa alami [4]. Dalam memproses bahasa alami manusia, perlu adanya proses yang dapat melakukan analisis sintaksis terhadap struktur kalimat. Salah satu metode dalam menganalisis sintaksis kalimat adalah stemming.

Algoritma Stemming adalah proses melakukan normalisasi pada kata seperti penghapusan prefiks (awalan), sufiks (akhiran), dan standarisasi tanda-tanda lainnya, sehingga proses ini mereduksi semua kata menjadi bentuk umum atau bentuk dasarnya [5]. Salah satu varian dari algoritma stemming adalah algoritma Light Stemming. Algoritma Light Stemming adalah algoritma yang hanya menghilangkan imbuhan depan (prefix) dan imbuhan belakang (sufix) [6].

\section{METODOLOGI}

\section{1) Kamus Ilmu Nahwu}

Langkah pertama dalam penelitian ini adalah membuatkan KamusIlmuNahwu yang berisi kombinasi unicode per kata. Contoh isi kamus kata ilmu nahwu tersebut adalah sebagai berikut:

$1573 ; 0 ; 1604 ; 0 ; 1609 ; 0 ;=$ Harfun Al-Jarr $1601 ; 0 ; 1610 ; 0 ; 1607 ; 0 ;=$ Harfun Al - A'tof $1581 ; 0 ; 1578 ; 0 ; 1609 ; 0 ;=\mathrm{Isim}$ $1571 ; 0 ; 1606 ; 0 ; 1575 ; 0 ;=$ Isim Dhomir

$1608 ; 1575 ; 1604 ;=$ Isim Ma'rifah $1576 ; 1575 ; 1604 ;=$ Isim Ma'rifah $1601 ; 1575 ; 1604 ;=I s i m$ Ma'rifah $1573 ; 0 ; 1584 ; 0 ;=$ Harfun Tanbih $1575 ; 0 ; 1606 ; 0 ;=$ Harfun Syartin $1573 ; 0 ; 1604 ; 0 ; 1575 ; 0 ;=$ Harfun Istisna $1603 ; 1614 ; 1610 ; 1618 ;=$ Harfun An-Nasab

Kamus kata ilmu nahwu tersebut disimpan dalam file txt agar proses pencariannya lebih cepat. Semakin banyak isi kamus kata tersebut, dapat menentukan tingkat akurasi pendeteksian struktur kalimat bahasa Arab.

\section{2) Unicoding}

Dalam memproses kalimat berbahasa Arab, diperlukan proses yang harus dilakukan sebelum melakukan stemming, yaitu proses unicoding. Pada proses unicoding, kalimat bahasa Arab dikonversi menjadi kode tertentu sesuai dengan kode standar komputer agar dapat diproses pengolahan katanya. Alur proses unicoding dijelaskan dalam Gambar 1.

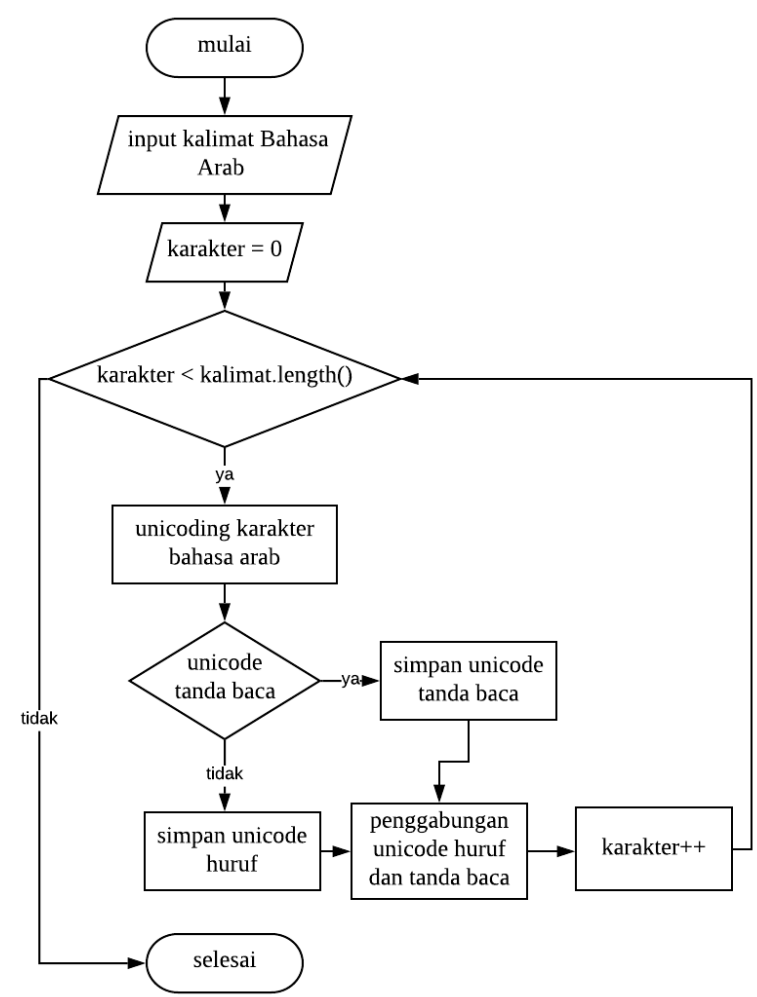

Gambar 1. Flowchart Unicoding

Pada proses unicoding, kalimat yang diinput diubah menjadi unicode terlebih dahulu, kemudian dipisahkan antara unicode tanda baca seperti huruf, kemudian hasil masing-masing unicode ditampung dalam sebuah variabel dengan ditambahkan tanda titik-koma (;) di akhir huruf sehingga tidak menghilangkan keaslian unicode per karakter tersebut. Tabel unicode tanda baca dan huruf bahasa Arab dapat dilihat pada Tabel 1 dan Tabel 2 dibawah ini. 
Tabel 1. Unicode Tanda Baca Arab

\begin{tabular}{|c|c|}
\hline Tanda Baca & Unicode \\
\hline 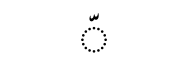 & 1617 \\
\hline$\overline{-}$ & 1614 \\
\hline 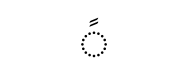 & 1611 \\
\hline$\stackrel{8}{\circ}$ & 1615 \\
\hline$\ddot{8}$ & 1612 \\
\hline ? & 1616 \\
\hline 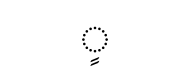 & 1613 \\
\hline$\stackrel{\circ}{\circ}$ & 1618 \\
\hline
\end{tabular}

Tabel 2. Unicode Huruf Arab

\begin{tabular}{|c|c|}
\hline Unicode & Huruf \\
\hline 1575 & 1 \\
\hline 1576 & ب ب \\
\hline 1577 & $\ddot{0}$ \\
\hline 1578 & ت \\
\hline 1579 & $\dot{H}$ \\
\hline 1580 & ج \\
\hline 1581 & $\tau$ \\
\hline 1582 & $\dot{\tau}$ \\
\hline 1583 & د \\
\hline 1584 & $j$ \\
\hline 1585 & J \\
\hline 1586 & j \\
\hline 1587 & س \\
\hline 1588 & ش ش \\
\hline 1589 & ص \\
\hline 1590 & ض \\
\hline
\end{tabular}

\begin{tabular}{|c|c|}
\hline Unicode & Huruf \\
\hline 1591 & b \\
\hline 1592 & $\ddot{b}$ \\
\hline 1593 & $\varepsilon$ \\
\hline 1594 & $\dot{\varepsilon}$ \\
\hline 1600 & . \\
\hline 1601 & ف \\
\hline 1602 & ق \\
\hline 1603 & ك \\
\hline 1604 & $J$ \\
\hline 1605 & p \\
\hline 1606 & ن \\
\hline 1607 & $\circ$ \\
\hline 1608 & 9 \\
\hline 1609 & s \\
\hline 1610 & ي \\
\hline 1591 & b \\
\hline
\end{tabular}

\section{3) Rule Ilmu Nahwu}

Setelah proses unicoding dan light stemming, maka langkah selanjutnya adalah membaca hasil stemming sesuai dengan rule ilmu nahwu. Berikut penjelasan mengenai rule ilmu nahwu:

\section{a) Isim}

Isim (kata benda) adalah setiap kata yang mempunyai arti benda, baik konkret maupun abstrak, tanpa ada unsur waktu di dalamnya. Isim memiliki ciri khusus yang membedakannya dengan jenis kata lain. Cirinya antara lain:

- Diawali dengan al ( ال ( ).

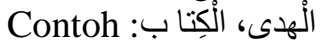

- Diakhiri dengan tanwin.

Contoh : كِتابٌ

- Diawali salah satu huruf jar.

Huruf jar tersebut adalah :

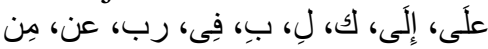

- Diawali diawali oleh huruf nida.

Contoh : با ادم = با + آكادم

- Disandarkan (diidlofatkan) kepada kata benda lainnya, kebanyakan untuk menunjukkan pemilikan.

b) Fi'il

Fi'il (kata kerja) adalah kata yang menunjukkan suatu pekerjaan yang berkaitan dengan waktu, baik lampau, sekarang, maupun yang akan datang. Oleh karena itu, kata kerja (fi'il) dalam bahasa arab juga di bedakan menjadi tiga macam yaitu: fi'il madi (lampau), fi'il mudari' (sekarang dan akan datang) dan fi'il amr (perintah). Ciri khas dari fi'il sebagai berikut :

- Diawali قُ .

Contoh : قََ أَفْلَ تَّل

- Diawali salah satu huruf mudlori'

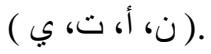

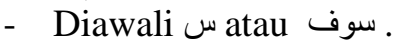

Contoh : تعلَمونَ، سوف سيُقِق ل

- Diakhiri dengan Ta' taknis $(ت)$.

ربحت : Contoh

- Diakhiri dengan Ta' fa'il

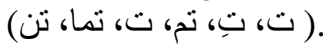

- Diakhiri dengan Naa fa'il (نا). انزَلْنا: Contoh

\section{c) Harf}

Harf adalah setiap kata yang tidak akan memiliki makna kecuali menyertainya dengan kata yang lain. Harf atau huruf dipandang sebagai kata tugas atau kata penghubung [7]. 


\section{4) Pemeriksaan pada Kamus Kata}

Stemming yang dilakukan dengan tambahan proses dalam menentukan kata yang harus distemming yaitu pemilihan kata baku, agar kata yang distemming merupakan kata yang memang harus dicari kata dasarnya, bukan sebaliknya. Dengan proses pemilihan kata ini, proses stemming lebih efektif dan lebih cepat. Alur pemilihan kata dijelaskan melalui flowchart pada Gambar 2 di bawah ini.

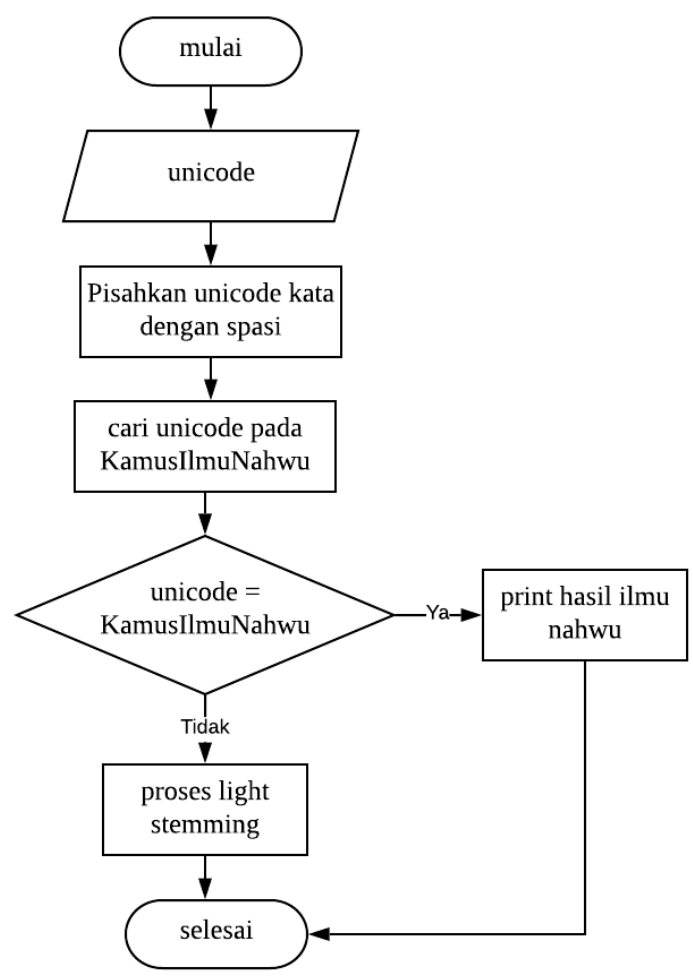

Gambar 2. Flowchart Pemeriksaan pada Kamus Kata

Alur dari proses filtering kata dijelaskan di bawah ini:

a. Input diambil dari hasil proses unicoding.

b. Sistem melakukan proses pemisahan per kata dengan dipisahkan spasi, kemudian unicode kata yang sudah dipisahkan, disimpan dalam variabel array sesuai dengan urutan kata tersebut.

c. Selanjutnya sistem mencari kombinasi unicode kata dasar berdasarkan KamusIlmuNahwu yang telah dibuat sebelumnya. Jika terdapat unicode kata di dalam kamus kata, maka sistem akan langsung menampilkan hasil jenis katanya, jika tidak sesuai maka diproses stemming menggunakan algoritma light stemming.

\section{5) Light Stemming}

Proses Light Stemming adalah proses Stemming yang lebih difokuskan pada imbuhan depan (prefix) dan imbuhan belakang (sufix), jadi Light Stemming ditekankan pada proses penghapusan imbuhan depan dan belakang secara simultan sesuai dengan rule dalam operasi Light Stemming berikut:

1. Jika kata tersebut jumlah hurufnya 4 atau lebih, hapus 3 karakter pertama pada kata jika karakternya adalah:

$$
\text { وال , بال , فال , كال , ولل , مال , ال , سال , لال }
$$

2. Jika kata tersebut jumlah hurufnya 4 atau lebih, hapus 2 karakter pertama jika karakternya adalah:

$$
\text { ول ,كا ,فبا , لل ,وم , وت ,وب , لا , سي ,وس , وي , }
$$

3. Jika kata tersebut jumlah hurufnya 4 atau lebih, dan diawali dengan huruf $و$ (waw), hapus g pada karakter pertama.

4. Jika kata tersebut jumlah hurufnya 4 atau lebih, dan diawali dengan huruf ب (ba') atau J (lam), maka hapus ب (ba') atau J (lam) pada kata tersebut.

5. Menghapus secara recursive 2 huruf pada belakang kata tersebut, jika kata tersebut jumlah hurufnya 4 atau lebih dan 2 huruf belakang tersebut termasuk dalam daftar ini:

$$
\begin{aligned}
& \text { ون , ات , ان , ين , تن , تم , كن , كم, هن , يا , ني , } \\
& \text { وا , ما , نا, هم , ية , هان , ها }
\end{aligned}
$$

6. Menghapus secara recursive 1 huruf pada belakang kata tersebut, jika kata tersebut jumlah hurufnya 3 atau lebih dan 1 huruf belakang tersebut adalah:

Dari rule di atas akan dihasilkan kata dasar berdasarkan imbuhan depan dan imbuhan belakang, tetapi tidak menutup kemungkinan juga bahwa ada perbedaan arti pada sebuah kata setelah di stemming. Sebagai contoh adalah kata الملكة yang artinya adalah seorang ratu, setelah ada penghilangan menjadi ملك yang artinya adalah seorang raja.

Dari rule di atas, maka menghasilkan daftar imbuhan depan dan imbuhan belakang dalam ilmu nahwu sesuai Tabel 3 dan Tabel 4 di bawah ini: 
Tabel 3. Unicode Imbuhan Depan (prefix)

\begin{tabular}{|c|c|}
\hline Imbuhan & Unicode \\
\hline 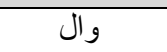 & $1608 ; 1575 ; 1604$ \\
\hline بال & $1576 ; 1575 ; 1604$ \\
\hline فال & 1601;1575;1604; \\
\hline كال & $1603 ; 1575 ; 1604$ \\
\hline ولل - ن ال & $1608 ; 1604 ; 1604$ \\
\hline 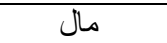 & $1605 ; 1575 ; 1604$ \\
\hline ال ال & $1575 ; 1575 ; 1604$ \\
\hline 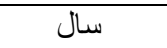 & $1587 ; 1575 ; 1604$ \\
\hline لال & $1604 ; 1575 ; 1604$ \\
\hline 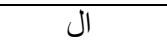 & 1575;1604; \\
\hline g & 1608;1575; \\
\hline لل & 1604;1604; \\
\hline وم & 1608;1605; \\
\hline
\end{tabular}

Tabel 3 Lanjutan. Unicode Imbuhan Depan (prefix)

\begin{tabular}{|c|c|}
\hline Imbuhan & Unicode \\
\hline وت & 1608;1578; \\
\hline وب & 1608;1576; \\
\hline$y$ & $1604 ; 1575$ \\
\hline سى & 1587;1610; \\
\hline وس & 1608;1587; \\
\hline وى & $1608 ; 1610$ \\
\hline ول & 1608;1604; \\
\hline 5 & $1603 ; 1575$ \\
\hline فا & $1601 ; 1575$ \\
\hline
\end{tabular}

Tabel 4. Unicode Imbuhan Belakang (sufix)

\begin{tabular}{|c|c|}
\hline Imbuhan & Unicode \\
\hline$ي$ & $1610 ; 1575 ;$ \\
\hline$ن$ & $1608 ; 1606 ;$ \\
\hline$ن$ & $1610 ; 1606 ;$ \\
\hline$ن$ & $1575 ; 1578 ;$ \\
\hline$ن$ & $1606 ; 1575 ;$ \\
\hline ات كن & $1603 ; 1605 ;$ \\
\hline ه ه & $1603 ; 1606 ;$ \\
\hline ه & $1607 ; 1605 ;$ \\
\hline
\end{tabular}

\begin{tabular}{|c|c|}
\hline هن & $1607 ; 1606$ \\
\hline ان & $1575 ; 1606$ \\
\hline با & $1576 ; 1575$ \\
\hline ما & $1605 ; 1575$ \\
\hline ت & 1578 \\
\hline و & $1608 ; 1575$ \\
\hline ني & $1606 ; 1610$ \\
\hline يا & 1610;1575; \\
\hline ية & $1610 ; 1577$ \\
\hline ي & 1610 \\
\hline o & 1607 \\
\hline ب & 1576; \\
\hline$\ddot{z}$ & 1577 \\
\hline تم & $1578 ; 1605$ \\
\hline تن & 1578;1606; \\
\hline
\end{tabular}

Dari identifikasi imbuhan depan dan imbuhan belakang pada proses Light Stemming di atas didapatkan sebuah rule yang digunakan untuk menentukan ilmu nahwu yang dapat dilihat pada Tabel 5, Tabel 6, dan Tabel 7:

Tabel 5. Rule Imbuhan pada Fi'il Madhi

\begin{tabular}{|c|c|}
\hline $\begin{array}{c}\text { Imbuhan } \\
\text { Depan }\end{array}$ & $\begin{array}{l}\text { Imbuhan } \\
\text { Belakang }\end{array}$ \\
\hline kosong & تن \\
\hline kosong & تم \\
\hline kosong & نا \\
\hline kosong & تما \\
\hline kosong & 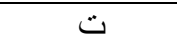 \\
\hline kosong & 1 \\
\hline kosong & با \\
\hline kosong & و وا \\
\hline kosong & ما \\
\hline kosong & ها \\
\hline
\end{tabular}

Tabel 6. Rule Imbuhan pada Fi'il Mudhari'

\begin{tabular}{|c|c|}
\hline $\begin{array}{c}\text { Imbuhan } \\
\text { Depan }\end{array}$ & $\begin{array}{c}\text { Imbuhan } \\
\text { Belakang }\end{array}$ \\
\hline و & kosong \\
\hline$ע$ & ksoong \\
\hline$س ى$ & kosong \\
\hline$س$ & kosong \\
\hline وس & kosong \\
\hline
\end{tabular}




\begin{tabular}{|c|c|}
\hline سال & kosong \\
\hline وت & ان \\
\hline$\gamma$ & ان \\
\hline سىى & ان \\
\hline وس & ان \\
\hline وى & ان \\
\hline سال & ان \\
\hline وت & ون \\
\hline$y$ & ون \\
\hline سىى & ون \\
\hline وس & ون \\
\hline وى & ون \\
\hline سال & ون \\
\hline وت & 1 \\
\hline $\bar{y}$ & 1 \\
\hline سىى & 1 \\
\hline وس & 1 \\
\hline وى & 1 \\
\hline سال & 1 \\
\hline وت & ن \\
\hline وى & ن \\
\hline
\end{tabular}

Tabel 7. Rule Imbuhan pada Isim

\begin{tabular}{|c|c|}
\hline $\begin{array}{c}\text { Imbuhan } \\
\text { Depan }\end{array}$ & $\begin{array}{l}\text { Imbuhan } \\
\text { Belakang }\end{array}$ \\
\hline ال & Kosong \\
\hline و ال & Kosong \\
\hline بال & Kosong \\
\hline فال & Kosong \\
\hline كال & Kosong \\
\hline مال & Kosong \\
\hline III & Kosong \\
\hline لال & Kosong \\
\hline لل & Kosong \\
\hline ولل & Kosong \\
\hline ول & Kosong \\
\hline 5 & Kosong \\
\hline فا & Kosong \\
\hline با & Kosong \\
\hline وب & Kosong \\
\hline ب & Kosong \\
\hline
\end{tabular}

Dengan teridentifikasinya rule tersebut maka sistem akan lebih mudah mendeteksi ilmu nahwu pada setiap kata, rule dibuat berdasarkan proses light Stemming, pada beberapa imbuhan sudah di gabungkan dengan tambahan harfun yang melekat pada kata nya, jadi sudah termasuk mengedintifikasi kata sebelumnya.
Pada harfun, identifikasi langsung berdasarkan kecocokan kata, karena harfun merupakan kata yang paten jika berada di tengah kalimat tanpa menggandeng pada kata terseut, jadi langsung diberikan hasil. Tidak di berikan rule yang signifikan.

\section{HASIL DAN PEMBAHASAN}

Untuk melakukan uji coba proses light stemming pada kalimat bahasa Arab, maka diperlukan sebuah perangkat lunak. Perangkat lunak yang digunakan untuk pengujian dibangun menggunakan bahasa pemrograman Java. Kemudian dilakukan 3 kali pengujian pada kalimat yang berbeda.

\section{1) Pengujian 1}

Pengujian 1 dilakukan terhadap kalimat yang terdiri dari 50 kata, sebagai berikut:

لم يكن الصبي يذعن إذعانا. كان تحرشها به

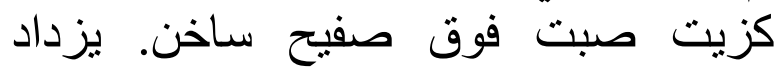

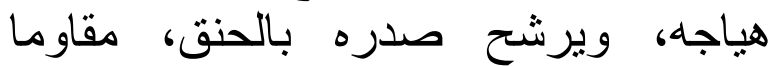

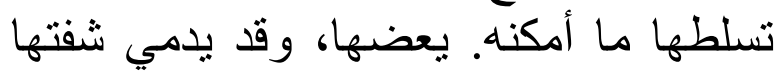

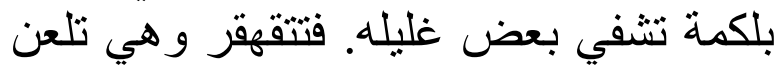

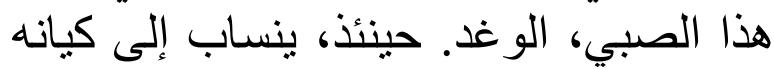

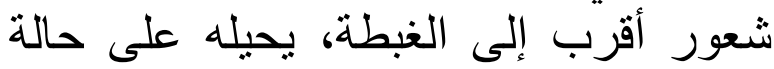
من الدعة و الصفاء

Detail hasil pendeteksian paragraf di atas ditampilkan dalam Tabel 8 di bawah ini.

Tabel 8. Hasil Pengujian 1

\begin{tabular}{|c|c|c|c|c|}
\hline No. & $\begin{array}{l}\text { Kata } \\
\text { Asli }\end{array}$ & $\begin{array}{l}\text { Kata } \\
\text { Dasar }\end{array}$ & $\begin{array}{c}\text { Hasil } \\
\text { Deteksi }\end{array}$ & Koreksi \\
\hline 1 & 4 & لم & $\begin{array}{l}\text { Harfun Al- } \\
\text { Jazm }\end{array}$ & \\
\hline 2 & يكن & يكن & Fiil Mudhari' & \\
\hline 3 & الصبي & صبي & Isim & \\
\hline 4 & 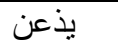 & 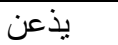 & Fiil Mudhari' & \\
\hline 5 & إذعانا & 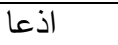 & Fiil Madhi & \\
\hline 6 & كان & كان & Fiil & \\
\hline 7 & تحرشها & تحرشها & Fiil Mudhari' & \\
\hline 8 & به & به & Fiil & Harf Jar \\
\hline 9 & كزيت & كز & $\begin{array}{l}\text { Isim } \\
\text { Maushul }\end{array}$ & \\
\hline 10 & صبت & صبت & Fiil & \\
\hline
\end{tabular}




\begin{tabular}{|c|c|c|c|c|c|c|c|c|}
\hline \multirow{2}{*}{$\begin{array}{l}11 \\
12\end{array}$} & فوق & فوق & Fiil & Isim & & & & Jarr \\
\hline & صفيح & صفيح & Fiil & Isim & 49 & الدعة & دعة & Isim \\
\hline 13 & ساخن & ساخن & Fiil & & 50 & الصفاء & صفاء & Isim \\
\hline
\end{tabular}

Hasil percobaan 1 terdapat 6 kesalahan dari 50 kata yang diinputkan. Sehingga kata yang benar adalah 44 kata.

\section{2) Pengujian 2}

Pengujian 2 dilakukan terhadap kalimat yang terdiri dari 42 kata sebagai berikut:

إحدى قدميه كعجلة مطاطية فار غة كليا من الهو اء، تعلق بجسده كطرف غريب، لهابه لا تتفعه في شيء، بل تعيق حركته ولهوه باستمر ار. لطالما خامرته فكرة الفكالك منها، فحاول ذئه ذلك عبثنا، بيديه لأول مرة، ثم بأظافره و أسنانه فيما بعد، بلا فائدة، ودائما بلا فاطون فائدة

Hasil deteksi kalimat, dituangkan dalam Tabel 9 di bawah ini.

Tabel 9. Hasil Pengujian 2

\begin{tabular}{|c|c|l|l|l|}
\hline No. & $\begin{array}{c}\text { Kata } \\
\text { Asli }\end{array}$ & $\begin{array}{c}\text { Kata } \\
\text { Dasar }\end{array}$ & $\begin{array}{c}\text { Hasil } \\
\text { Deteksi }\end{array}$ & Koreksi \\
\hline 1 & Fiil & $\begin{array}{l}\text { Isim } \\
\text { mufrod } \\
\text { tunggal }\end{array}$ & \\
\hline 2 & قدميك & $\begin{array}{l}\text { Isim } \\
\text { Mu'annas }\end{array}$ & \\
\hline 3 & كعل & &
\end{tabular}

Tabel 9 Lanjutan. Hasil Pengujian 2

\begin{tabular}{|c|c|c|c|c|}
\hline No. & $\begin{array}{l}\text { Kata } \\
\text { Asli }\end{array}$ & $\begin{array}{c}\text { Kata } \\
\text { Dasar }\end{array}$ & $\begin{array}{c}\text { Hasil } \\
\text { Deteksi }\end{array}$ & Koreksi \\
\hline 38 & ينساب & ينساب & Fiil Mudhari' & \\
\hline 39 & إلى & الى & $\begin{array}{l}\text { Harfun Al- } \\
\text { Jarr }\end{array}$ & \\
\hline 40 & كيانه & كيان & $\begin{array}{l}\text { Isim Mufrod } \\
\text { Tunggal }\end{array}$ & \\
\hline 41 & شعور & شعور & Fiil & \\
\hline 42 & أقرب & اقرب & Fiil & \\
\hline 43 & إلى & الى & $\begin{array}{l}\text { Harfun Al- } \\
\text { Jarr }\end{array}$ & \\
\hline 44 & الغبطة، & غبطة، & Isim & \\
\hline 45 & يحيله & يحيله & Fiil Mudhari' & \\
\hline 46 & على & على & $\begin{array}{l}\text { Harfun Al- } \\
\text { Jarr }\end{array}$ & \\
\hline 47 & حالة & حال & $\begin{array}{l}\text { Isim } \\
\text { Mu'annas }\end{array}$ & \\
\hline 48 & من & من & Harfun Al- & \\
\hline
\end{tabular}

\begin{tabular}{|c|c|c|c|c|}
\hline No. & $\begin{array}{l}\text { Kata } \\
\text { Asli }\end{array}$ & $\begin{array}{c}\text { Kata } \\
\text { Dasar }\end{array}$ & $\begin{array}{c}\text { Hasil } \\
\text { Deteksi }\end{array}$ & Koreksi \\
\hline 4 & مطاطية & مطاط & $\begin{array}{l}\text { Isim } \\
\text { Mu'annas }\end{array}$ & \\
\hline 5 & فار غة & رغة & Isim & \\
\hline 6 & كليا & كليا & Fiil & Isim \\
\hline 7 & من & من & $\begin{array}{l}\text { Harfun Al- } \\
\text { Jarr }\end{array}$ & \\
\hline 8 & الهو اء & هو اء & Isim & \\
\hline 9 & تعلق & تعلق & $\begin{array}{l}\text { Fiil } \\
\text { Mudhari' }\end{array}$ & \\
\hline 10 & بجسده & جسد & Isim & \\
\hline 11 & كطرف & كطرف & Fiil & \\
\hline 12 & غريب & غريب & Fiil & \\
\hline 13 & $\gamma$ & $y$ & $\begin{array}{l}\text { Harfun Al- } \\
\text { Jawab }\end{array}$ & \\
\hline
\end{tabular}




\begin{tabular}{|c|c|c|c|c|}
\hline 14 & تنفعه & تتفعه & $\begin{array}{l}\text { Fiil } \\
\text { Mudhari' }\end{array}$ & \\
\hline 15 & في & في & $\begin{array}{l}\text { Harfun Al- } \\
\text { Jarr }\end{array}$ & \\
\hline 16 & شيء & شيء & Fiil & Isim \\
\hline 17 & بَّل & بَّل & Harfun Al- & \\
\hline
\end{tabular}

\begin{tabular}{|l|l|l|l|l|} 
& & & 'Ataf & \\
\hline 18 & تعيق & $\begin{array}{l}\text { Fiil } \\
\text { Mudhari' }\end{array}$ & \\
\hline 19 & & & Isim & \\
\hline
\end{tabular}

\begin{tabular}{|c|c|c|c|}
\hline 19 & حركته & حركت & $\begin{array}{l}\text { Isim } \\
\text { Mufrod } \\
\text { Tungogal }\end{array}$ \\
\hline
\end{tabular}

\begin{tabular}{|c|c|c|c|c|}
\hline & & & Tunggal & \\
\hline 20 & لهوه & لهو & $\begin{array}{l}\text { Isim } \\
\text { Mufrod } \\
\text { Tunggal }\end{array}$ & \\
\hline 21 & باستمر ار & ستمر ار & Isim & \\
\hline
\end{tabular}

\begin{tabular}{|c|c|c|c|c|}
\hline 22 & لطالما & طال & Fiil & Isim \\
\hline 23 & خامرته & خامرت & Isim & \\
\hline
\end{tabular}

\begin{tabular}{|c|c|c|c|}
\hline $2 J$ & rat & 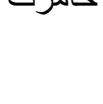 & $\begin{array}{l}\text { Mufrod } \\
\text { Tunggal }\end{array}$ \\
\hline 24 & فكرة & فكر & $\begin{array}{l}\text { Isim } \\
\text { Mu'annas }\end{array}$ \\
\hline
\end{tabular}

\begin{tabular}{|c|c|c|c|c|}
\hline & & & Mu'annas & \\
\hline 25 & الفكالك & فكاك & Isim & \\
\hline 26 & منها & مis & Fiil & Harfun \\
\hline
\end{tabular}

\begin{tabular}{|c|c|c|c|c|}
\hline & منه| & منهو & Fill & ctun \\
\hline 27 & فحاول & فحاول & Fiil & Isim \\
\hline 28 & ذذلك & ذلك & Fiil & Isim \\
\hline 29 & عبثا & عبثا & Fiil & Isim \\
\hline
\end{tabular}

\begin{tabular}{|c|c|c|c|c|}
\hline 29 & عبتا & عبتا & Fiil & Isim \\
\hline 30 & بيديه & بيدي & Isim & \\
\hline 31 & لأول & لاول & Fiil & Isim \\
\hline 32 & مرة & مرة & Fiil & Isim \\
\hline
\end{tabular}

\begin{tabular}{|c|c|c|c|c|}
\hline 32 & مرة & مرة & Fiil & Isim \\
\hline 33 & ثم & ثم & $\begin{array}{l}\text { Harfun Al- } \\
\text { 'Ataf }\end{array}$ & \\
\hline 34 & بأظافره & اظافر & Isim & \\
\hline 35 & أسنانه & اسنان & $\begin{array}{l}\text { Isim } \\
\text { Mufrod } \\
\text { Tunggal }\end{array}$ & \\
\hline 36 & فيما & فيما & Fiil & \\
\hline 37 & بعد & بعد & Fiil & Isim \\
\hline
\end{tabular}

Tabel 9 Lanjutan. Hasil Pengujian 2

\begin{tabular}{|c|c|c|c|c|}
\hline No. & $\begin{array}{r}\text { Kata } \\
\text { Asli } \\
\end{array}$ & $\begin{array}{l}\text { Kata } \\
\text { Dasar }\end{array}$ & $\begin{array}{c}\text { Hasil } \\
\text { Deteksi }\end{array}$ & Koreksi \\
\hline 38 & بلا & بلا & Fiil & $\begin{array}{l}\text { Harfun } \\
\text { Al- } \\
\text { Jawab }\end{array}$ \\
\hline 39 & فائدة & ئدة & Isim & \\
\hline 40 & دائما & دائ ن دائ & Fiil Madhi & \\
\hline 41 & بلا & بلا & Fiil & $\begin{array}{l}\text { Harfun } \\
\text { Al- } \\
\text { Jawab }\end{array}$ \\
\hline 42 & فائدة & 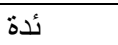 & Isim & \\
\hline
\end{tabular}

Hasil pengujian 2 terdapat 13 kesalahan dari 42 kata yang diinputkan. Sehingga kata yang benar adalah 29 kata.

\section{3) Pengujian 3}

Pengujian 3 dilakukan terhadap kalimat yang terdiri dari 43 kata, sebagai berikut:

تر اجعت للور اء وصدر ها بعلو وينخفظ،

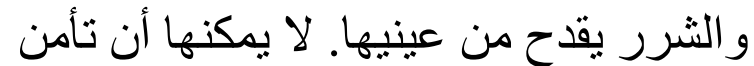

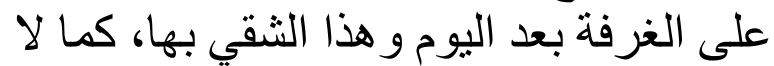
يمكنها أن تأمن على حياته إن نركته لئه يلهو

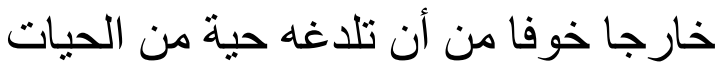
الكثر التي تستوطن الدغل القريب

Hasil deteksi kalimat, dituangkan dalam Tabel 10 di bawah ini.

Tabel 10. Hasil Pengujian 3

\begin{tabular}{|c|c|c|c|c|}
\hline No. & $\begin{array}{c}\text { Kata } \\
\text { Asli }\end{array}$ & $\begin{array}{c}\text { Kata } \\
\text { Dasar }\end{array}$ & $\begin{array}{c}\text { Hasil } \\
\text { Deteksi }\end{array}$ & Koreksi \\
\hline 1 & تراجعت & تراجعت & $\begin{array}{l}\text { Fiil } \\
\text { Mudhari' }\end{array}$ & \\
\hline 2 & للور اء & ور راء & Isim & \\
\hline 3 & صدر ها & صدر & Fiil Madhi & \\
\hline 4 & يعلو & بعلو & $\begin{array}{l}\text { Fiil } \\
\text { Mudhari' }\end{array}$ & \\
\hline 5 & ينخفظ، & ينخفظ، & $\begin{array}{l}\text { Fiil } \\
\text { Mudhari' }\end{array}$ & \\
\hline 6 & الثرر & شرر & Isim & \\
\hline 7 & يقدح & يقدح & $\begin{array}{l}\text { Fiil } \\
\text { Mudhari' }\end{array}$ & \\
\hline 8 & من & من & $\begin{array}{l}\text { Harfun Al- } \\
\text { Jarr }\end{array}$ & \\
\hline 9 & عينيها & عين & $\begin{array}{l}\text { Isim } \\
\text { Maushul }\end{array}$ & \\
\hline 10 & $\gamma$ & $y$ & $\begin{array}{l}\text { Harfun Al- } \\
\text { Jawab }\end{array}$ & \\
\hline
\end{tabular}

Tabel 10 Lanjutan. Hasil Pengujian 3

\begin{tabular}{|c|c|c|c|c|}
\hline No. & $\begin{array}{l}\text { Kata } \\
\text { Asli }\end{array}$ & $\begin{array}{l}\text { Kata } \\
\text { Dasar }\end{array}$ & $\begin{array}{c}\text { Hasil } \\
\text { Deteksi }\end{array}$ & Koreksi \\
\hline 11 & يمكنها & يمكنها & $\begin{array}{l}\text { Fiil } \\
\text { Mudhari' }\end{array}$ & \\
\hline 12 & أن & ان & $\begin{array}{l}\text { Harfun } \\
\text { Nahyi }\end{array}$ & \\
\hline 13 & تأمن & تامن & $\begin{array}{l}\text { Fiil } \\
\text { Mudhari' }\end{array}$ & \\
\hline
\end{tabular}




\begin{tabular}{|c|l|l|l|l|}
\hline 14 & على & $\begin{array}{l}\text { Harfun Al- } \\
\text { Jarr }\end{array}$ & \\
\hline 15 & غرف الغرفة & $\begin{array}{l}\text { Isim } \\
\text { Ma'rifah }\end{array}$ & \\
\hline & & & (2) &
\end{tabular}

\begin{tabular}{|l|l|l|l|}
\hline 43 & قريب & Isim \\
\hline
\end{tabular}

Hasil pengujian 3 terdapat 5 kesalahan dari 43 kata yang diinputkan. Sehingga kata yang benar adalah 38 kata.

\section{4) Evaluasi Hasil Pengujian}

Dari 3 kali pengujian di atas, dapat dihitung tingkat akurasinya dengan rumus:

\begin{tabular}{|l|}
\hline jumlah kata yang benar \\
\hline jumlah keseluruhan kata \\
\hline
\end{tabular}

Maka hasil perhitungan tingkat akurasinya adalah sebagai berikut:

$$
\begin{aligned}
& 44+29+38 \text { kata } \\
& -50+42+43 \text { kata }
\end{aligned}
$$

Dari hasil pengujian, tingkat akurasi algoritma Light Stemming terhadap deteksi struktur kalimat bahasa Arab adalah sebesar 82.22\%. Maka tingkat error atau kesalahan dalam deteksinya bernilai $\mathbf{1 7 . 7 8 \%}$.

Kesalahan-kesalahan yang terjadi pada hasil deteksi, terjadi karena beberapa hal, yaitu:

a. Jika kata tidak memiliki imbuhan, baik imbuhan depan maupun imbuhan belakang, maka sistem secara otomatis mendeteksi jenis kata tersebut merupakan fi'il, padahal pada kenyataannya tidak selalu $f i$ 'il, karena bisa jadi kata tersebut isim. Sebagai contoh pada kata: صرخ pada peletakan katanya صرخ bisa bermakna fi'il madhi karena bisa berakhiran fathah, tetapi pada peletakan kata yang berbeda, kata ini bisa berakhiran tanwin, pada saat kata ini menjadi tanwin, maka kata ini termasuk isim.

b. Gagalnya hasil deteksi juga dikarenakan tidak mampu melakukan stemming pada kata yang imbuhannya ditengah, karena memang proses light stemming hanya menghilangkan imbuhan depan dan imbuhan belakang.

\section{SIMPULAN DAN SARAN}

Dalam memproses bahasa Arab dengan komputer, maka diperlukan proses unicoding 
yaitu mengkonversi atau mengubah karakter bahasa Arab menjadi kode tertentu sesuai dengan kode standar komputer yang disebut sebagai unicode agar dapat diproses lebih lanjut. Proses unicoding ini dilakukan pada huruf maupun pada tanda bacanya.

Algoritma Light Stemming dapat mendeteksi struktur kalimat bahasa Arab dengan tingkat akurasi yang baik yaitu sebesar 82,22\%. Kesalahan sebesar $17.78 \%$ dalam deteksi terjadi karena 2 hal, yaitu: (1) kata yang tidak memiliki imbuhan secara otomatis terdeteksi sebagai fi'il, padahal kata tanpa imbuhan tidak selalu $f i$ ' $i l$, bisa jadi kata tersebut berjenis isim, (2) tidak mampu melakukan stemming pada kata yang imbuhannya ditengah. Hasil deteksi struktur kalimat kata bahasa Arab terdiri dari 3 jenis, yaitu: isim, fi'il, dan harf, meskipun ada sub-sub jenisnya seperti isim ma'rifah, fi'il mudhari', harfun al-jar, dan lain-lain.

\section{REFERENSI}

[1] Gary F. Simons and Charles D. Fenning, "Ethnologue: Languages of the World, Twenty-first edition". Dallas, Texas: SIL International, 2018. Online version: https://www.ethnologue.com/21.

[2] Mukhlis, "Dasar-Dasar Bahasa Arab". Yogyakarta: Pustaka Insan Madani, 2007.
[3] Ari Wahyudi, "Langkah-Langkah Untuk Bisa Membaca Kitab Arab Gundul", Muslim.Or.Id, 13 April 2013. [Online]. Tersedia: https://muslim.or.id/13164langkah-langkah-untuk-bisa-membacakitab-arab-gundul.html [Diakses: 26 September 2019].

[4] R. Raman Nair and L. Sulochana Devi, "Sankrit Informatics: Informatics for Sankrit Studies and Research", Kerala: Centre for Informatics Research and Development, 2011.

[5] Maqbool R. Al-Maimani, Ahmed AlNaamany, Ahmed Zaki Abu Bakar, "Searching For Arabic-based Contents: An Approach Towards Using Arabic Derivatives", in International Conference on Communication, Computer and Power (ICCCP), February 2009.

[6] Aito Chen and Fredric Gey, "Building Arabic Stemmer for Information Retrieval". Berkeley: University of California. 2003.

[7] Muh. Haris Zubaidillah, "Pengantar Ilmu Nahwu Belajar Bahasa Arab Sampai Bisa". Hulu Sungai Utara: Amuntai Hemat. 